\title{
Research on Automobile Service Engineering Specialty Based on Talents Training of Excellent Engineers
}

\author{
Cenglin Yao \\ School of Mechanical and Electrical Engineering and Automotive Services, Wuhan Business \\ University, Wuhan, Hubei, 430056, China
}

Keywords: Excellent engineer; automotive service engineering; talent training mode

\begin{abstract}
The Ministry of Education's “Excellent Engineer Education and Training Program" is a major measure to promote China's engineering education powers to engineering education powers. The program aims to cultivate a large number of high-quality engineers and technicians with high innovation ability and adapt to the needs of economic and social development, and to serve the country in the path of new industrialization development, building an innovative country and strengthening the country. In combination with the talent training model of excellent engineers, it is proposed to adopt the application-oriented engineer training mode, that is, adopt the " $3+1$ " mode, three years of internship in the school, and one year of study in the enterprise and graduation design. As a teaching-oriented institution, the target orientation of engineering talent training should be emphasized and applied, laying a solid foundation for the next step of engineering master training. In view of the existing problems in the training model of automobile service engineering talents, the research and reform of the training program for automotive service engineering professionals is carried out in response to the requirements of the excellent engineer training program, so that it can better adapt to the requirements of cultivating high-quality engineers.
\end{abstract}

\section{Introduction}

With the continuous expansion of the enrollment scale of higher education institutions in China, the increasing investment in education, the gradual improvement of teaching facilities, the large investment in professional construction and the frequent increase in cooperation between schools and enterprises, China's higher education has achieved rapid development. It has trained thousands of graduates of various majors to meet the needs of China's rapid economic growth and made important contributions to China's rapid economic development. After years of development, the engineering education of higher education institutions has already had better conditions, which can basically meet the large demand of enterprises and projects of all levels and types of society. However, on the whole, the training of engineers in the construction industry can not meet the needs of China's rapid economic development. Due to the expansion of enrollment, the corresponding supporting measures, teacher strengths and practice bases failed to keep up, making the quality of college education not As far as practicable, college graduates do not have the basic qualities of engineers after entering the society, and can not carry out corresponding technical work, resulting in 
the overall low quality and ability of the construction industry[1].The current problems in engineer education are as follows:.

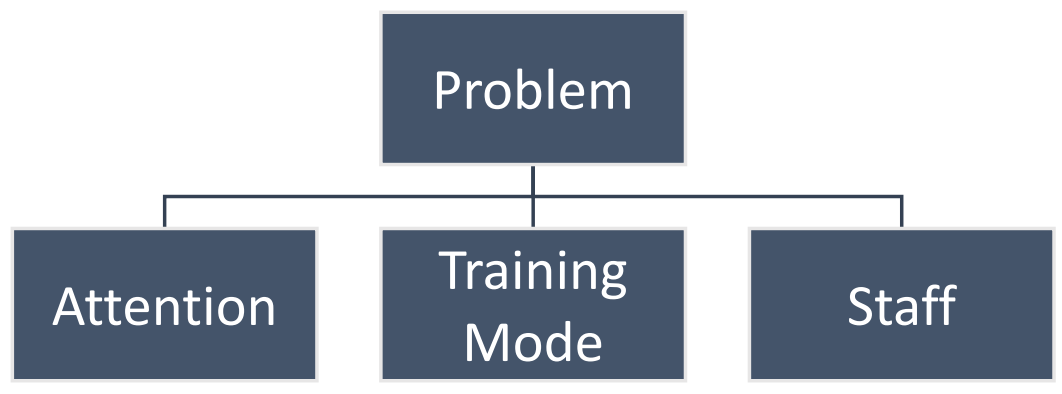

Figure 1 Current problems in engineer education

\subsection{Not enough attention}

China's higher education has always attached importance to science and has paid insufficient attention to engineering technology. Engineering colleges in all countries of the world train engineers, and we only pay attention to training engineers. Because in China, people generally have the concept of heavy science and light technology, and think that scientists are great and engineers are at a lower level. Many scientists even think that knowing science can do everything. As long as you understand science, engineering problems and technical problems will be solved. Slowly, in China, a style has emerged - heavy science and light technology[2].

\subsection{Defects in training mode}

The training of engineering talents in higher education institutions in China is a combination of classroom teaching and practical teaching. The purpose of classroom teaching is to enable students to master the basic knowledge and professional knowledge of the corresponding majors through the teaching of teachers, focusing on theoretical knowledge; practical teaching is an effective way to consolidate theoretical knowledge and deepen the understanding of theoretical knowledge, and to cultivate high quality with innovative consciousness. The important link of engineering and technical personnel is an important platform for linking theory with practice and cultivating students to master scientific methods and improve their hands-on ability. China's current engineer training model has so far focused on subject knowledge transfer. There are still many shortcomings in the practice and training of practical ability and innovation ability, such as the practice base construction, the organizational management of practical teaching, and the importance of practical teaching[3].

\subsection{The lack of high-quality teaching staff}

The comprehensive quality of teachers in higher education directly determines the quality of teaching. The level of the faculty's business level is the key factor in cultivating qualified engineers. The engineering management major is a relatively new profession. Since its development, the faculty has always been the main reason for restricting the rapid development of the profession, especially the lack of high-level professional teachers. At present, the professional background of college engineering management teachers is quite different, some of which are engineering backgrounds such as civil engineering, water conservancy and hydropower engineering, industrial 
engineering, etc., and the other part is the economic management professional background of engineering economy, enterprise management, information management, etc. There is no uniform standard[4]. Therefore, it is necessary to strengthen the training of engineering management professional teachers, especially the re-education of young teachers; in addition, we should increase the intensity of talent introduction, change the standards for talent introduction, and introduce more high-quality, high-level talents, preferably Academic leaders who enrich work experience and business leaders in related industries.

\section{Research plan}

\subsection{Rationally determine talent training objectives according to the needs of enterprises}

The establishment of the application-oriented excellence engineer training objectives should be based on the actual needs of the enterprise, carry out differential positioning, and take the road of dislocation development of academic training objectives. The formulation of training objectives should highlight the application characteristics.

\subsection{Building three major educational platforms around the training objectives}

In order to meet the above-mentioned knowledge, ability and quality requirements of engineering application talents, and to achieve the goal of application-oriented talent training, it is necessary to construct an engineering application-oriented talent training program that meets the needs of the economy and society. In accordance with the requirements for talent training of outstanding engineers, the construction of three major education platforms, namely, the construction of curriculum platforms, the construction of skill platforms, and the construction of comprehensive quality platforms.

\subsection{Renewing ideas and exploring new ways for application-oriented engineers to develop}

The cultivation of applied talents should eliminate the drawbacks of traditional engineering education, and take the promotion of people's all-round development and adaptation to economic and social development as the starting point and the foothold of talent training. As a teacher of imparting knowledge, the teacher should update the concept, establish a sense of responsibility, comprehensively reform the way of training talents, jump out of the traditional teaching mode, and emphasize the engineering-oriented reality in the teaching content, especially new technologies and new achievements. Enter the classroom.

\section{Research content}

\subsection{Develop a training program for automotive service engineering professionals based on the Excellence Engineers Program}

Cultivate the comprehensive development of morality, intelligence, beauty, and foundation, solid foundation, broad knowledge, strong practical ability, high comprehensive quality, innovative spirit, systematically mastering professional basic theories, professional knowledge and basic skills, and engaged in engineering manufacturing, engineering construction, engineering operation. Or the theoretical basis and practical ability of specialized technical work, engineering application-oriented senior professionals with engineers' cultural literacy and professional ethics[5]. 


\subsection{Course website construction}

The cultivation of the excellent engineer program is inseparable from the reform of the curriculum construction. The core professional courses of the automotive service engineering profession include automobile service engineering, automobile marketing, automobile insurance and claims, and automobile service enterprise management. Courses are imperative, and it is necessary to construct course websites for these professional courses in accordance with the training requirements of excellent engineers.

\subsection{Practice Teaching Reform}

The practical teaching content plays a vital role in the training of excellent engineers. Based on the experimental conditions of the college itself, the existing equipment is fully utilized, the number of equipment sets is increased, the time input for the practical teaching links is increased, and the practical teaching is organized scientifically and reasonably. Link to meet the requirements of the ability of outstanding engineers to develop. The training of excellent engineers must involve the participation and support of enterprises. The automotive service engineering profession will further increase the intensity of internships, increase the intensity of enterprise internship practice, cultivate students' labor consciousness and professional quality, and realize the absence of students to professional people. During the enterprise study, the engineer, as a part-time teacher, teaches students the transfer of theoretical textbooks to practical textbooks, teaches theoretical principles, teaches practical high-end technology, and shifts basic theoretical research to applied technology research, pays attention to the transformation of results, and realizes theory and practice. Organic combination.

\subsection{Construction of the practice base}

At present, the automotive service engineering professions include Jiangsu Senfeng Group, Dongfeng Yueda Kia Motors Co., Ltd., Jiangsu Aoxin New Energy Automobile Co., Ltd., Ma Hengda Yueda (Yancheng) Tractor Co., Ltd., etc., according to the training requirements of outstanding engineers, further improve At the same time as the construction of the above-mentioned enterprises' internship bases, we strive to arrange more students to conduct internships and strengthen engineering practice. In addition, 2-3 auto service companies will be contacted as an internship base to further increase the construction of the internship base.

\section{Conclusion}

In response to the Ministry of Education's excellence plan, Yancheng Institute of Technology is actively carrying out the implementation plan for outstanding engineers. As a mechanical discipline, the automotive engineering service profession is necessary to implement the excellent engineer training program, and the automotive engineering service profession is listed as the key construction discipline of the school. It is imperative to reform and innovate the automotive service engineering personnel training program and teaching system in accordance with the training requirements of excellent engineers. Taking the construction plan of the excellent engineers as an opportunity, the teaching reform of the automotive engineering service profession will help graduates to better learn the true knowledge of engineering practice and integrate into the practice environment of the enterprise more quickly after graduation. At the same time, it will also promote the improvement of teachers' engineering practice ability. 


\section{References}

[1]Claudia Sheinbaum-Pardo. Decomposition analysis from demand services to material production: The case of CO 2 emissions from steel produced for automobiles in Mexico[J]. Applied Energy,2016,174.

[2]Ziqi Song,Yi He,Lihui Zhang. Integrated planning of park-and-ride facilities and transit service[J]. Transportation Research Part C,2017,74.

[3]Chanam Lee,Jeongjae Yoon,Xuemei Zhu. From sedentary to active school commute: Multi-level factors associated with travel mode shifts [J]. Preventive Medicine,2016.

[4]Haobing Liu,Yanzhi “Ann” Xu,Nicholas Stockwell,Michael O. Rodgers,Randall Guensler. A comparative life-cycle energy and emissions analysis for intercity passenger transportation in the U.S. by aviation, intercity bus, and automobile[J]. Transportation Research Part D,2016,48.

[5]Qing Shen,Peng Chen,Haixiao Pan. Factors affecting car ownership and mode choice in rail transit-supported suburbs of a large Chinese city[J]. Transportation Research Part A,2016,94. 